\title{
Pandemi Tak Berarti Surut Rejeki: Studi Kasus Social Media Marketing Strategies Pada Usaha Mikro Berbasis Rumah "Pawon Bu Puspa"
}

\author{
Anggraeni Wulandari ${ }^{\mathrm{a}, 1, *}$ \\ a Perwakilan BKKBN DIY, Jl. Kenari No. 58 Umbulharjo, Yogyakarta, 55165, Indonesia \\ ${ }^{1}$ anggra.wulan7@gmail.com \\ *penulis korespondensi
}

\begin{abstract}
In order to survive from Covid-19 pandemic, several micro businesses have grown in the community. However, not all of the have been able to develop properly. This study aims to determine the steps to use social media as a marketing strategy for the home-based business namely "Pawon Bu Puspa", in order to answer the concerns of micro business activists in implementing marketing strategies during a pandemic. This research is qualitative with a case study approach. Data collection using online observation and online interviews. The sample selection technique used purposive sampling to selected informants on the use of social media in marketing the Micro Business "Pawon Bu Puspa" in during a pandemic in Solo City. The study found that the use of social media in marketing is very safe and effective in the midst of a pandemic situation. It is safe because buyers and sellers interact via social media and it is effective because the turnover of "Pawon Bu Puspa" has tended to be stable from the beginning of the pandemic until now. The social media used in marketing: WhatsApp and Instagram. The results of the research can be used as a reference for the successful use of social media in the marketing strategy of micro businesses in the midst of a pandemic.
\end{abstract}

Keywords: culinary business, home-based micro business, social media marketing strategies, the Covid-19 pandemic

\section{ABSTRAK}

Sebagai langkah bertahan hidup, beberapa usaha mikro tumbuh di tengah masyarakat. Meskipun demikian, usaha yang tumbuh di tengah pandemi ini, tidak semua mampu berkembang dengan baik. Penelitian ini bertujuan mengetahui langkah penggunaan media sosial sebagai strategi pemasaran usaha mikro berbasis rumah yaitu "Pawon Bu Puspa", guna menjawab keresahan penggiat usaha mikro dalam melakukan strategi pemasaran saat pandemi. Penelitian ini adalah kualitatif dengan pendekatan studi kasus. Pengumpulan data menggunakan pengamatan daring dan wawancara secara daring. Teknik pemilihan sampel menggunakan purposive sampling kepada narasumber terpilih, tentang pemanfaatan media sosial dalam pemasaran Usaha Mikro "Pawon Bu Puspa" pada saat pandemi di Kota Surakarta. Hasil penelitian menemukan bahwa pemanfaatan media sosial dalam pemasaran, sangat aman dan efektif di tengah situasi pandemi. Aman karena pembeli dan penjual berinteraksi lewat media sosial dan efektif karena omset "Pawon Bu Puspa" cenderung stabil dari awal pandemi hingga kini. Media sosial yang digunakan dalam pemasaran diantaranya adalah WhatsApp dan Instagram. Konten yang ditayangkan adalah produk dan pengetahuan seputar produk yang dipasarkan, baik manfaat maupun testimoni dari pelanggan. Selain aktif di akun Instagram "Pawon Bu Puspa", pemasaran juga aktif pada akun Instagram pribadinya dan nomor WhatsApp admin "Pawon Bu Puspa". Hasil penelitian dapat menjadi rujukan keberhasilan penggunaan media sosial dalam strategi pemasaran usaha mikro di tengah kondisi pandemi.

Kata Kunci: bisnis kuliner, pandemi Covid-19, strategi pemasaran media sosial, usaha mikro berbasis rumah 


\section{Pendahuluan}

Pepatah jawa "Ora Obah, Ora Mamah", memiliki filosofi bahwa ketika seseorang tidak mau berusaha maka dia tidak akan bisa makan (hidup). Guna meneruskan kehidupan, banyak cara dipilih. Ada yang memilih menjadi karyawan, ada juga yang memilih menggeluti usaha tertentu. Saat pandemi Covid-19 menyerang dunia Tahun 2020 banyak karyawan yang diputus hubungan kerjanya, banyak usaha yang terpaksa tutup karena bangkrut. Akan tetapi ternyata banyak benih bisnis baru yang tumbuh karena keharusan bertahan hidup para pelakunya, tidak terkecuali sektor kuliner/bisnis makanan.

Bisnis makanan/sektor kuliner tidak hanya menarik untuk diamati dari sisi ragamnya akan tetapi juga dari sisi produksi dan pemasarannya. Dalam penelitian ini, peneliti fokus pada strategi pemasaran salah satu usaha mikro di bidang kuliner yaitu "Pawon Bu Puspa". Tujuan penelitian ini adalah mengetahui langkah penggunaan media sosial sebagai strategi pemasaran produk makanan milik "Pawon Bu Puspa", guna menjawab keresahan penggiat usaha mikro dalam melakukan strategi pemasaran yang efektif saat pandemi.

\section{Usaha Mikro Berbasis Rumah}

Menurut Undang-undang Republik Indonesia Nomor 20 Tahun 2008 tentang Usaha Mikro, Kecil dan Menengah (Indonesia, 2008), usaha mikro didefinisikan sebagai:

"usaha produktif milik orang perorangan dan/atau badan usaha perorangan yang memenuhi kriteria Usaha Mikro yaitu:

a. memiliki kekayaan bersih paling banyak Rp50.000.000,00 (lima puluh juta rupiah) tidak termasuk tanah dan bangunan tempat usaha; atau

b. memiliki hasil penjualan tahunan paling banyak Rp300.000.000,00 (tiga ratus juta rupiah)."

Kemudian, usaha mikro berbasis rumah diterjemahkan sebagai (Sayers, 2010) " $A$ business entity operated by a self-employed person working at or from home selling commodities or services in the market'. Usaha mikro berbasis rumah adalah badan usaha yang dijalankan oleh wiraswasta yang bekerja di atau dari rumah, yang menjual komoditas atau jasa di pasar. Berdasarkan studi terdahulu, usaha mikro berbasis rumah (Mason, Carter, \& Tagg, 2011) memperkuat ekonomi lokal dengan penciptaan lapangan kerja dan melalui hubungan komersial mereka. Usaha ini juga meningkatkan keselamatan dan keamanan mereka karena bekerja di lingkungan rumah, dan menjadi salah satu sarana mencapai keseimbangan dalam kehidupan kerja. Disampaikan demikian karena memungkinkan orang yang terikat dengan rumah (karena misalnya memiliki tanggung jawab merawat anggota keluarga yang sakit atau sudah lansia), dapat memperoleh pemasukan finansial.

Usaha mikro berbasis rumah terbagi menjadi dua yaitu (Clark \& Douglas, 2014): 1.) usaha yang beroperasi di rumah, dimana sebagian besar pekerjaan dilakukan di tempat tinggal pemilik (contoh: kegiatan akunting, praktik pekerjaan, dll) ; dan 2.) usaha yang beroperasi dari rumah, dimana pemilik/operator melakukan sebagian besar pekerjaan di lapangan atau di tempat klien, tetapi administrasi-pencatatan-persediaan dilakukan di rumah (contoh: sektor jasa tukang kayu, sektor jasa tukang ledeng, dll). Dalam penelitian ini, "Pawon Bu Puspa" termasuk dalam definisi "usaha mikro yang beroperasi di rumah" karena seluruh proses produksi, penciptaan ide, akunting, pemasaran dilaksanakan di rumah. 


\section{Media Sosial}

Menurut Daniel Miller (Miller et al., 2016) media sosial merupakan tempat di mana kita bersosialisasi, bukan hanya sarana berkomunikasi. Lebih lengkap dijelaskan oleh Maya W. Dollarhide (Dollarhide, 2020) bahwa media sosial adalah teknologi dengan basis komputer yang dapat memfasilitasi ide, pemikiran dan informasi melalui jaringan dan komunitas virtual. Media ini seringkali digunakan untuk bertukar pesan. Mayoritas media sosial yang kini berkembang, berbasis internet dan memberikan pengguna konten (informasi pribadi, dokumen, video, foto) komunikasi elektronik yang cepat. Pengguna terlibat dengan media sosial melalui komputer, tablet, atau ponsel cerdas serta melalui perangkat lunak berbasis web atau aplikasi web.

Masih menurut Maya E. Dollarhide, pada awal kemunculannya, media sosial hanya merupakan cara untuk berinteraksi dengan teman dan keluarga. Akan tetapi, media ini kemudian diadopsi oleh dunia bisnis yang ingin memanfaatkan metode komunikasi baru yang populer untuk menjangkau pelanggan. Media sosial menjadi favorit di dunia bisnia karena kemampuannya untuk terhubung dan berbagi informasi dengan siapa pun di dunia, atau dengan banyak orang dalam waktu bersamaan. Dalam penelitian ini, media sosial diadopsi oleh "Pawon Bu Puspa" sebagai sarana pemasaran produknya di tengah pandemi. Mengapa media sosial dipilih, karena selama pandemi terjadi keterbatasan gerak dalam pemasaran produk. Strategi pemasaran produk melalui media sosial dirasa mampu memenuhi ketentuan protokol kesehatan yang mengharuskan jaga jarak antar orang, melarang adanya kerumunan, dan mengurangi mobilitas.

\section{Social Media Marketing Strategies}

Dalam konteks marketing, media sosial merupakan platform yang digunakan untuk membangun relasi, membagi informasi dan/atau mempengaruhi (Kaplan \& Haenlein, 2010). Media sosial dalam strategi marketing, (Holliman \& Rowley, 2014) telah banyak digunakan sebagai alat komunikasi untuk tujuan branding dan word of mouth (WOM). Media sosial telah menghasilkan tiga perubahan mendasar di pasar ( $\mathrm{Li}$, Larimo, \& Leonidou, 2021) yaitu: 1.) Media sosial memungkinkan perusahaan dan pelanggan untuk terhubung dengan cara yang tidak mungkin dilakukan di masa lalu; 2.) Media sosial mengubah cara perusahaan dan

pelanggan berinteraksi dan saling mempengaruhi; 3.) Pertumbuhan data media sosial yang cepat, memungkinkan perusahaan untuk mengelola hubungan lebih baik dengan pelanggan dan meningkatkan keyakinan pengambilan keputusan dalam bisnis.

Social media marketing strategies (SMMS) terbagi menjadi empat jenis (Li et al., 2021) berdasarkan peningkatan kematangan dari segi: strategi perdagangan sosial, strategi konten sosial, strategi pemantauan sosial, dan strategi manajemen hubungan pelanggan. Empat jenis SMMS tersebut adalah: 1.) Social Commerce Strategy; 2.) Social Content Strategy; 3.) Social Monitoring Strategy; 4.) Social Customer Relationship Management (CRM) Strategy. Pada penelitian ini, peneliti mengidentifikasi SMMS yang digunakan oleh Usaha Mikro Berbasis Rumah "Pawon Bu Puspa" adalah Social Monitoring Strategy.

Social Monitoring Strategy menurut Barger, diartikan sebagai "proses mendengarkan dan menanggapi customer, dimana marketer terlibat di dalam proses tersebut" (Barger, Peltier, \& Schultz, 2016). Social Monitoring Strategy dalam SMMS dicirikan oleh proses komunikasi dua arah, di mana inisiasi berasal dari pelanggan yang berkomentar dan 
berperilaku melalui media sosial, sedangkan perusahaan memanfaatkan data perilaku tersebut untuk mendengarkan, belajar/berkembang, dan bereaksi terhadap pelanggannya. Dalam penelitian ini, peneliti akan menganalisa langkah "Pawon Bu Puspa" dalam berkomunikasi dua arah (mendengar, belajar, bereaksi) dengan pelanggannya agar produknya laku dan tetap dilirik customer meskipun saat pandemi. Penelitian ini penting sebagai referensi akan bagaimana cara Usaha Mikro Berbasis Rumah menggunakan media sosial sebagai media pemasaran yang aman dan murah, agar usaha bertahan bahkan bangkit selama pandemi Covid-19.

\section{Metode Penelitian}

Penelitian mengenai SMMS pada Usaha Mikro Berbasis Rumah "Pawon Bu Puspa" ini, merupakan studi kualitatif dengan pendekatan studi kasus. Metode pengambilan data yang digunakan adalah pengamatan daring dan wawancara secara daring kepada narasumber terpilih dengan bantuan WhatsApp Video Call. Menurut Creswell (Creswell, 2007), "interviewing is the most widely used form of data collection in qualitative research". Meskipun demikian, apabila kondisi tertentu terjadi dalam penelitian, misalnya keterbatasan waktu, keterbatasan pendanaan, wilayah penelitian yang tersebar dan keterbatasan mobilitas dalam penelitian, maka interview secara konvensional/tatap muka bisa digantikan dengan wawancara secara daring. Wawancara daring diterjemahkan Janet Salmons (Salmons, 2015) sebagai setiap dialog atau observasi yang dilakukan untuk tujuan pengumpulan data. Wawancara daring bisa berupa percakapan lisan atau tertulis, baik direncanakan dengan hati-hati atau berupa percakapan santai. Dengan kata lain, bahkan pesan teks singkat atau obrolan cepat melalui situs media sosial bisa dianggap sebagai wawancara dengan peserta saat pengumpulan data.

Pengambilan sampel menggunakan teknik purposive sampling dimana narasumber yang menjadi pusat penelitian adalah pemilik sekaligus marketer "Pawon Bu Puspa" yaitu Puspa Kumalasari. Alasan pemilihan bisnis kuliner "Pawon Bu Puspa" sebagai sumber data penelitian ini adalah karena "Pawon Bu Puspa" tumbuh dan sukses pada saat pandemi Covid-19; Usaha Mikro-Kecil-Menengah (UMKM) percontohan di Kecamatan Pasarkliwon di bawah binaan Pusat Layanan Usaha Terpadu (PLUT) Kota Surakarta; produknya telah menarik perhatian televisi dalam dan luar kota kategori bisnis kuliner; omset stabil dari awal berdiri hingga kini; serta adanya testimoni positif dari pelanggan. Penelitian berlangsung dari bulan April 2020-Januari 2021 di Kota Surakarta. Penelitian ini hanya terbatas pada analisa langkah "Pawon Bu Puspa" dalam menggunakan Social Monitoring Strategy sebagai bagian dari SMMS guna berkomunikasi dua arah (mendengar, belajar, bereaksi) dengan pelanggannya agar produknya laku dan tetap dilirik customer meskipun saat pandemi. Pengembangan penelitian mengenai proses produksi hingga proses sertifikasi makanan pada Usaha Mikro Berbasis Rumah "Pawon Bu Puspa" masih terbuka bagi peneliti lain untuk penelitian lanjutan.

\section{Hasil dan Pembahasan}

Usaha Mikro Berbasis Rumah dengan nama "Pawon Bu Puspa", didirikan di Kota Surakarta pada tanggal 27 April 2020. Ide awal didirikannya usaha ini adalah keinginan untuk menjadi pelopor masakan rumah yang tahan lama, sehat, enak, ekonomis, turut serta 
mengkampanyekan Gerakan Memasyarakatkan Makan Ikan (GEMARIKAN) dan menjadi lauk favorit saat pandemi Covid-19. "Pawon Bu Puspa" diinisiasi oleh ibu dan anak yaitu Ibu Puspaningsih dan Puspa Kumalasari. Ibu dan anak ini menggeluti usaha dengan menggunakan rumah tinggal mereka yang bertempat di Kelurahan Semanggi, Kecamatan Pasarkliwon sebagai lokasi usaha. Sistem pengiriman produk menggunakan Cash On Delivery (COD) untuk wilayah Kota Surakarta, kemudian menggunakan ekspedisi/kargo untuk pengiriman luar kota. Marketplace yang digunakan untuk memasarkan produk "Pawon Bu Puspa" adalah Tokopedia, Shopee dan Instagram. Sistem penjualan pada bisnis kuliner ini, menggunakan sistem reseller dan penjualan langsung. Reseller produk "Pawon Bu Puspa" sudah tersedia di Kota Surabaya, Kota Jakarta Barat, Kota Jakarta Pusat dan Kota Yogyakarta.

Produk yang disediakan oleh "Pawon Bu Puspa" hingga kini, meliputi: Kering Ikan (Varian Original, Pedas Pas, dan Pedas Nampol), Kering Ayam (Varian Original dan Pedas), dan Almond (Varian Asin, Bawang Putih, Susu). Produk Kering Ikan dan Kering Ayam diproduksi sendiri oleh ibu dan anak ini, sedangkan untuk produk Almond mereka bekerjasama dengan pihak ketiga. Dari produk yang tersedia, produk andalan "Pawon $\mathrm{Bu}$ Puspa" adalah Kering Ikan. Usaha kuliner ini memiliki omset stabil antara 1-2 juta setiap bulannya, terhitung sejak April 2020 hingga Desember 2020. Menurut pernyataan dari pemiliknya yaitu Puspa Kumalasari, usaha ini kini dalam proses mengurus Izin Produk Industri Rumah Tangga (P-IRT) agar jangkauan usahanya semakin luas dan kualitas produk dapat terstandar.

"Saat ini kami telah selesai mengajukan syarat pemberian izin produk industri rumah tangga (P-IRT) ke Dinas Kesehatan Kota Yogyakarta, tinggal menunggu izin keluar. Rencana jika izin keluar kami akan melebarkan sayap ke toko oleh-oleh di Kota Surakarta dan sekitarnya" (Puspa Kumalasari, 2021)

Usaha mikro berbasis rumah "Pawon Bu Puspa" telah dihubungi beberapa media mainstream dan daring untuk diliput yaitu S TV dan Kresna TV, serta channel milik Mimoto Studio pada platform Youtube dengan link https://youtu.be/fxk8h6ugY5I. Pemilik "Pawon Bu Puspa" juga melakukan kerjasama dengan Dinas Koperasi dan UKM Kota Surakarta untuk pemasaran produk melalui Indomaret dan mengikuti program "Big Promo" yang dibuat Kementerian Pariwisata dan Ekonomi Kreatif

\subsection{Langkah Pemasaran Melalui Media Sosial}

Pemasaran melalui Instagram "pawonbupuspa" dan Instagram pemilik yaitu "elisabethsarii":

- Pemilik melakukan pengambilan foto dan video produk jadi, kemudian diunggah pada platform Instagram.

- Pertama-tama, pemilik mengunggah akun "Pawon Bu Puspa" pada akun pribadinya "elisabethsarii" agar khalayak mengetahui akun produk kuliner tersebut. Pemilik "Pawon Bu Puspa" diuntungkan dengan jumlah followernya yang cukup banyak saat itu (April 2020), yaitu mencapai 732 orang 
- Foto diunggah pada feed Instagram akun "Pawon Bu Puspa" dengan keterangan: jenis, berat, manfaat, hashtag yang memungkinkan produk dikenal masyarakat luas

- Video diunggah pada stories Instagram kedua akun dengan keterangan: jumlah produk yang masih tersedia, jumlah produk yang terjual

- Pada bagian highlight akun Instagram "Pawon Bu Puspa", dicantumkan testimoni positif dari para pelanggan produk (Gambar 3.1)

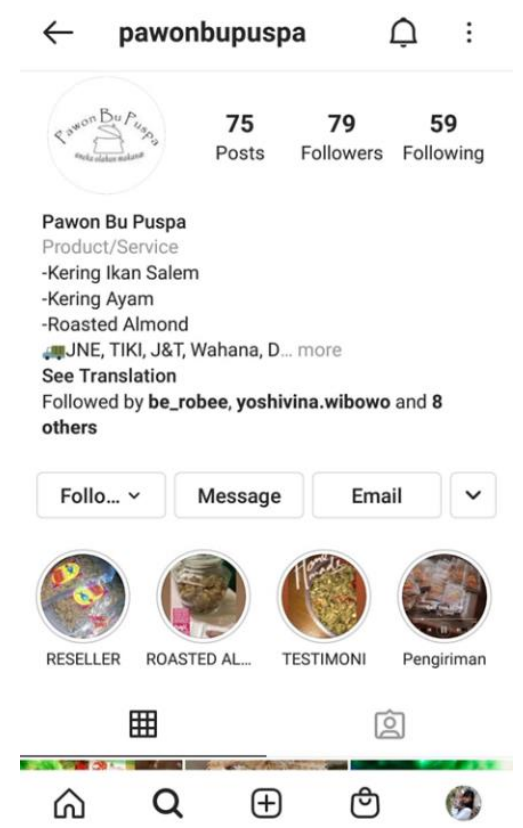

Gambar 3.1 Pencantuman Testimoni Positif Instagram pada Bagian Highlight Instagram

- Update stok dilakukan setiap hari lewat stories dua akun Instagram tersebut

- Foto dan video produk di update setiap hari lewat stories kedua akun Instagram tersebut

- Kata-kata yang digunakan pemilik untuk memantik rasa penasaran biasanya adalah "nasi satu porsi kurang kalo dimakan pake lauk ikan kering", "awas ketagihan", "stok terbatas untuk besok, siapa cepat dia dapat".

Pemasaran melalui WhatsApp:

- Sebelum membuat akun Instagram "Pawon Bu Puspa", pemilik mengirimkan contoh produk kepada beberapa calon pelanggan untuk menerima masukan. Para calon pelanggan ini dikontak melalui WhatsApp

- Pemilik mengunggah foto, video dan testimoni produk pada status WhatsApp setiap hari.

- Melakukan private chat kepada reseller tentang stok barang, update harga dan material promosi yang mereka butuhkan (bisa foto, bisa video).

Tindakan ini sama dengan langkah pemasaran melalui WhatsApp yang pernah diteliti oleh Prihatna "WhatsApp Status enables enhanced relationships where it is also related to 
the theory of attachment where customers innately form and maintain proximal attachments with resellers, as revealed by interviewees that from just knowing the product, the user can eventually become a regular customer." (Prihatna, Ayal, Sistarani, \& Christanti, 2019)

\subsection{Permasalahan Seputar Kualitas Produk}

- Kemasan toples produk "Kering Ikan" pecah saat pengiriman, keluhan disampaikan lewat WhatsApp

- Produk "Kering Ikan" terasa agak basi saat diterima pelanggan , keluhan disampaikan lewat WhatsApp

\subsection{Cara pemilik menanggapi keluhan dari pelanggan, yaitu:}

- Meminta maaf kepada pelanggan, disampaikan lewat WhatsApp

- Meminta masukan dari pelanggan, disampaikan lewat WhatsApp

- Memberikan ganti rugi kepada pelanggan dengan mengirimkan produk pengganti.

\subsection{Pengembangan Produk yang Telah Dilakukan}

- Kemasan toples digantikan dengan kemasan plastik vakum untuk pengiriman luar kota, agar peristiwa toples produk yang pecah tidak terulang (Gambar 2).

- Logo dan label mengalami perubahan, dari yang awalnya hanya hitam putih, menjadi berwarna, produk yang awalnya tidak menyertakan komposisi dan tangga kadaluarsa, kemudian menyertakan keterangan tersebut setelah pengembangan.
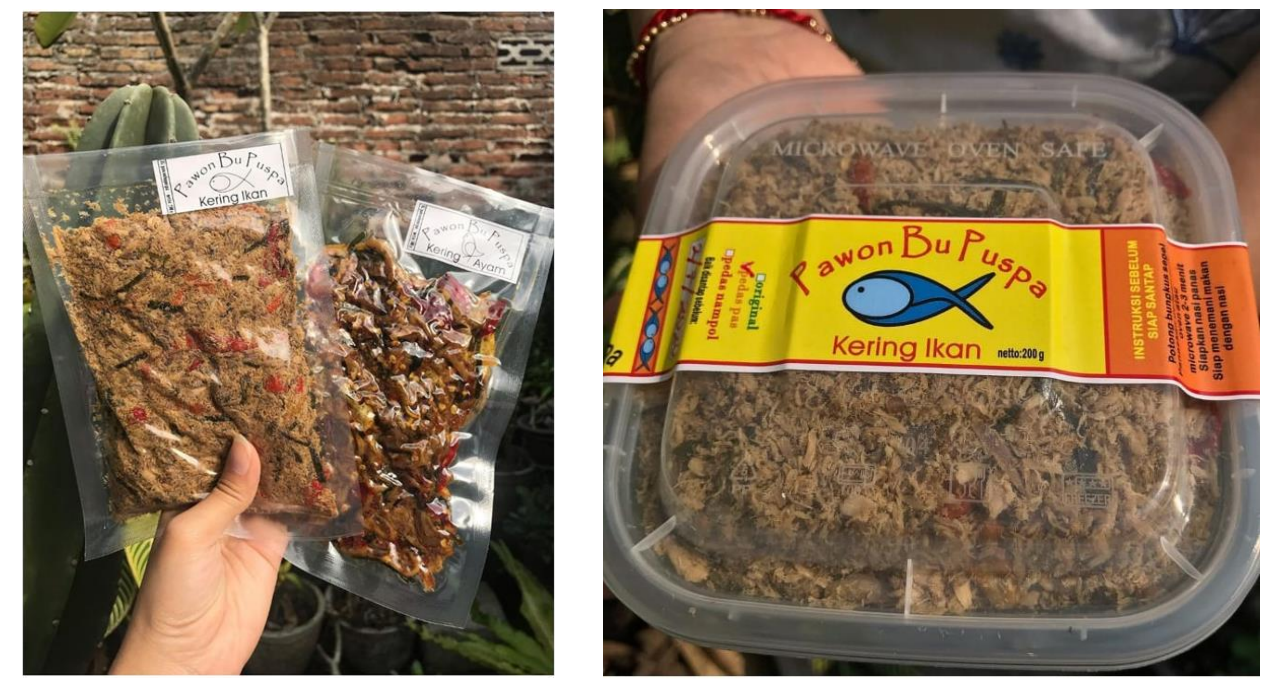

Gambar 3.2 Logo-label Lama VS Baru

- Produk "Kering Ayam" tercipta setelah muncul permintaan dari pelanggan yang alergi produk makanan laut.

- Produk "Almond" ada karena muncul keluhan dari pelanggan yang menyukai produk "Kering Ikan" tetapi takut kolesterol jahatnya naik, sehingga butuh produk penyeimbang. 
Pengembangan produk merupakan salah satu faktor penting dalam menjaga kepuasan pelanggan. Disebutkan dalam penelitian terdahulu oleh Ershadi bahwa "concentration on the customer, continuous improvement and teamwork have a positive significant relationship with customer satisfaction" (Ershadi, 2019)

Hasil penelitian mengenai penerapan SMMS pada "Pawon Bu Puspa", apabila kita analisis dengan indikator Social Monitoring Strategy, maka memang benar bahwa:

- Telah terjadi proses komunikasi dua arah antara pihak "Pawon Bu Puspa" dengan pelanggan melalui media sosial: terbukti dengan banyaknya obrolan yang masuk melalui akun Instagram dan WhatsApp terkait produk "Pawon Bu Puspa"

"Dalam sehari bisa lebih dari 500 chat dan komentar dari akun

Instaram dan WhatsApp yang menanyakan tentang produk yang

dimiliki "Pawon Bu Puspa", kalo dituruti bisa ngga kemana-mana, cuma balas chat seharian"

(Puspa Kumalasari, 2021)

- Penjual mendengarkan masukan dari pelanggan: terbukti dari permintaan dari pihak "Pawon Bu Puspa" kepada beberapa pelanggan untuk memberikan review jujur dan masukan atas produk yang mereka miliki, dan memberikan contoh produk kepada calon pelanggan untuk memperoleh masukan atas produk yang akan launching.

- Penjual belajar/berkembang: terbukti dari perubahan logo-labelproduk menjadi lebih menarik; mengganti kemasan agar lebih aman saat pengiriman luar kota; menciptakan produk baru karena keluhan dari pelanggan yang alergi dan takut akan kolesterol jahat dalam tubuhnya

- Penjual memberikan reaksi (positif) atas keluhan pelanggan: terbukti dari penambahan produk yang menunjang kesehatan; pihak "Pawon Bu Puspa" mau meminta maaf saat produk tidak sesuai harapan pelanggan dan mengganti dengan produk yang sesuai harapan pelanggan

Proses ini sejalan dengan penelitian milik Li yang menyatakan bahwa "social monitoring strategy is not only to observe and analyze the behaviors of customers in social media, but also to actively search for and respond to customer online needs and complaints" (Li et al., 2021).

\section{Kesimpulan}

"Pawon Bu Puspa" merupakan salah satu dari banyak kisah sukses usaha yang tumbuh dan berkembang selama pandemi Covid-19 disaat usaha mikro lain tutup. Usaha mikro berbasis rumah ini sukses bertahan dengan strategi pemasaran berbasis media sosial. Strategi pemasaran dengan media sosial dinilai aman dan efektif sehubungan banyaknya keterbatasan diterapkan selama pandemi demi keamanan bersama. Penelitian ini menjadi bukti bahwa penggunaan media sosial, khususnya Instagram dan WhatsApp tidak perlu diragukan lagi manfaatnya oleh para penggiat usaha baru, apabila ingin usahanya maju dan dikenal masyarakat luas. Meminjam indikator dalam Social Monitoring Strategy, maka langkah yang harus diimplementasikan penggiat usaha agar penggunaan media sosial sebagai strategi pemasaran efektif dan membawa manfaat adalah: komunikasi dua arah 
yang baik antara penjual dan pembeli; kesediaan penjual untuk mendengarkan masukan dari pembeli; kesediaan penjual untuk selalu belajar/berkembang; dan kesediaan penjual untuk memberikan reaksi (positif) atas keluhan pelanggan. Dengan kemampuan memanfaatkan sisi positif media sosial, sukses berusaha di tengah pandemi bukan mustahil lagi.

\section{Ucapan Terima Kasih}

Terimakasih kepada pemilik "Pawon Bu Puspa" atas kesediaannya menceritakan pengalaman yang luar biasa, serta enumerator yang telah bersedia membantu peneliti sehingga pengumpulan data dan penyusunan tulisan ilmiah ini dapat berjalan dengan lancar. Sehat dan semangat selalu untuk kita semua.

\section{Pustaka}

Barger, V., Peltier, J. W., \& Schultz, D. E. (2016). Social media and consumer engagement: a review and research agenda. Journal of Research in Interactive Marketing, 10(4), 268-287. https://doi.org/10.1108/JRIM-06-2016-0065

Clark, D. N., \& Douglas, H. (2014). Micro-enterprise growth: Lessons from home-based business in New Zealand. Small Enterprise Research, 21(1), 82-98. https://doi.org/10.1080/13215906.2014.11082078

Creswell, J. W. (2007). Qualitative inquiry and research design: Choosing among five approaches (2nd ed.). Thousand Oaks, CA: Sage.

Dollarhide, M. E. (2020). Social media definition. Retrieved February 11, 2021, from https://www.investopedia.com/terms/s/social-media.asp

Ershadi, M. J. (2019). Measuring the impact of soft and hard total quality management factors on customer behavior based on the role of innovation and continuous improvement. 31(6), 1093-1115. https://doi.org/10.1108/TQM-11-2018-0182

Holliman, G., \& Rowley, J. (2014). Business to business digital content marketing: Marketers' perceptions of best practice. Journal of Research in Interactive Marketing, 8(4), 269-293. https://doi.org/10.1108/JRIM-02-2014-0013

Indonesia, P. R. Undang-undang Republik Indonesia No. 20 Tahun 2008 tentang Usaha Mikro, Kecil dan Menengah. , Pub. L. No. 20 (2008).

Kaplan, A. M., \& Haenlein, M. (2010). Users of the world, unite! The challenges and opportunities of Social Media. Business Horizons, 53(1), 59-68. https://doi.org/10.1016/j.bushor.2009.09.003

Li, F., Larimo, J., \& Leonidou, L. C. (2021). Social media marketing strategy: definition, conceptualization, taxonomy, validation, and future agenda. Journal of the Academy of Marketing Science, 49(1), 51-70. https://doi.org/10.1007/s11747-020-00733-3

Mason, C. M., Carter, S., \& Tagg, S. (2011). Invisible Businesses: The Characteristics of Home-Based Businesses in the United Kingdom. Regional Studies, 45(5), 625-639. https://doi.org/10.1080/00343401003614241

Miller, D., Costa, E., Haynes, N., McDonald, T., Nicolescu, R., Sinanan, J., ... Wang, X. (2016). How the World Changed Social Media. In How the World Changed Social Media (1st ed.). https://doi.org/10.2307/j.ctt1g69z35

Prihatna, K. A., Ayal, R., Sistarani, M., \& Christanti, Y. (2019). What Whatsapp status enables reseller to do as channel. International Journal of Innovative Technology and Exploring Engineering, $8(9 \quad$ Special Issue 3), 44-55. 
https://doi.org/10.35940/ijitee.I3009.0789S319

Salmons, J. (2015). Qualitative online interviews (2nd ed.; V. Knight, Ed.). London: Sage Publications Ltd.

Sayers, J. G. (2010). Home-based business in the city. Small Enterprise Research, 17(February), 165-176. https://doi.org/https://doi.org/10.5172/ser.17.2.165 